\title{
EFFECT OF STRESS HYPERGLYCEMIA, IN ACUTE ST SEGMENT ELEVATION MYOCARDIAL INFARCTION
}

\author{
IYAD ABBAS SALMAN ${ }^{1}$, LAYLA ALI HAKEEM ${ }^{2}$ \& FAHIM ALI HASSAN ${ }^{3}$ \\ ${ }^{I}$ M. B. Ch. B / Ficms (Ans. \& Icu) / Caba+Ic \\ ${ }^{2}$ M. B. Ch. B / Ficms (Ans. \& Icu) \\ ${ }^{3} \mathrm{M} . \mathrm{B} . \mathrm{Ch} . \mathrm{B} . \mathrm{Dr}$
}

Background

Stress hyperglycemia, after an acute myocardial infarction may be associated with increased risk of heart failure, cardiogenic shock, and death.

Objectives

- To study the effect of stress hyperglycemia, on the development of cardiogenic shock, heart failure, arrhythmia and death

- To determine, whether the site of myocardial infarction has an effect on development of stress hyperglycemia

- To determine, whether this hyperglycemia occurs more in patients, who receive thrombolytic therapy or in those who do not receive it.

Patients and methods

This study had enrolled 92 patients, with acute ST elevation myocardial infarction, who had no history of diabetes or heart failure, who were consecutively admitted to (emergency department then to CCU and medical ward) in Baghdad Teaching Hospital, during the period of one year between 1stof December, 2011 to 1st of December, 2012.

All of the patients had been thouroghly examined and sent for random plasma glucose and HbAlc; in addition ECG, cTn and echo cardiographic examination had been made, for all of them. Statistical analysis had been done, using student's T-test and Chi square test, according to the type of data to analyse. P value $<0.05$ had been selected as level of statistically significant association or difference.

Results

A total number of 92 patients were studied; Group 1: 60 patients (60\%) were normoglycemics, along their hospital admission.

Group 2: 32 patients(32\%) were hyperglycemics, due to myocardial infarction induced stress. 8 patients (8\%) were excluded from the study because, their HbAlc was elevated (they were considered undiagnosed DM).

The incidence of heart failure, cardiogenic shock and death were high in group 2. While, the incidence of cardiac arrhythmias is not significantly differed between group 1 and group 2 patients.

Extensive myocardial infarction occurred more frequent in group 2 patients.

Conclusions

- Stress hyperglycemia, is independently a poor prognostic factor in acute ST elevation myocardial infarction; it
\end{abstract}


is independently associated with increased incidence of heart failure, cardiogenic shock and death.

- Patients with extensive myocardial infarction are more liable, to get stress hyperglycemia.

- Stress hyperglycemia is not associated with increased incidence of cardiac arrhythmia.

- Stress hyperglycemia occurs more in patients, who receive thrombolytic therapy.

KEYWORDS: Stress Hyperglycemia \& Acute ST Elevation Myocardial Infarction

Received: Aug 31, 2017, Accepted: Sep 20, 2017, Published: Nov 02, 2017, Paper Id: IJMPSDEC20171

INTRODUCTION

\section{Acute Myocardial Infarction}

Pathophysiology

Acute coronary thrombosis, resulting in total occlusion of acoronary artery, leads to ST-segment elevation myocardial infarction (STEMI) (1). Exposition of the lipid-rich core, after atherosclerosis plaque rupture/erosion into the arterial lumen triggers the formation of unstable platelet aggregates, which may lead to intermittent reduction in coronary flow and cause distal embolization (2).

There are two basic types of acute myocardial infarction, based on pathology:

- Transmural: associated with atherosclerosis, involving a major coronary artery. It can be sub classified into anterior, posterior, inferior, lateral or sepal. Transmural infarcts extend, through the whole thickness of the heart muscle and are usually a result of complete occlusion of the area's blood supply. (3) In addition, on ECG, ST elevation and Q waves are seen.

- Subendocardial: involving a small area in the subendocardial wall of the left ventricle, ventricular septum, or papillary muscles. The subendocardial area is particularly susceptible to ischemia. (4)

\section{Risk Stratification}

Risk stratification of patients with STEMI can be based on physical examination findings at the time of presentation. The Killip classification is easy to use and provides a rapid method of risk-stratifying patients, in the emergency department, although the mortality rates may overestimate those in the modern era). (5)

Table: Killip Classification for Patients with STEMI (5)

\begin{tabular}{|l|c|}
\hline \multicolumn{1}{|c|}{ Killip Class } & $\begin{array}{c}\text { Hospital } \\
\text { Mortality (\%) }\end{array}$ \\
\hline I. No congestive heart failure & 6 \\
\hline $\begin{array}{l}\text { II. Mild congestive heart failure, rales, S3 } \\
\text { congestion on chest radiograph }\end{array}$ & 17 \\
\hline III. Pulmonary edema & 38 \\
\hline IV. Cardiogenic shock & 81 \\
\hline
\end{tabular}

\section{Diagnosis}

\section{Clinical Presentation}

The classic symptom of AMI is central substernal chest discomfort, that may radiate to the neck, back, or arms. 
The discomfort is persistent (unrelieved by rest or nitrates); is frequently associated with diaphoresis, nausea, dyspnea, and fear of impending death; and usually achieves maximum intensity over several minutes, at least $20 \%$ of patients with AMI, however, may lack classic chest discomfort and instead have atypical symptoms(6).

\section{Electrocardiographic Manifestations}

All patients presenting to an emergency department with chest pain or other symptoms, concerning for MI should have an electrocardiogram (ECG) performed and interpreted within 10 minutes of arrival. (7). The ECG remains the single most useful diagnostic test in cases of suspected ACS and facilitates segregation of patients into STEMI and NSTEACS pathways.(8). In NSTEACS, findings may be more variable and commonly include ST-segment depression and T-wave inversion. Criteria for acute ischemia have been validated and include ST-segment elevation of _1 mm that is concordant with the main vector of the QRS complex; ST-segment depression of _1 mm in leads V1, V2, or V3; and ST-segment elevation of _5 mm that is discordant with the main vector of the QRS complex.(9)

\section{Serum Markers in Acute Myocardial Infarction}

Damaged cardiomyocytes, release several proteins in the circulation, including myoglobin, creatine kinase (CK), and its MB isoenzyme (CK-MB), cardiac troponin (cTn) I and T, aspartate aminotransferase, and lactate dehydrogenase. The cTn biomarkers, are preferred based on superior sensitivity and specificity for cardiac injury and robust prognostic value, across the spectrum of ACS.(10-11)

\section{Stress Hyperglycemia}

Studies have shown that, an increase in glucose concentrations after admission for AMI and the overall glycemic load, after admission determine morbidity and mortality in this condition $(12,13)$. Recent guidelines have suggested that, glucose levels should be maintained below $140 \mathrm{mg} / \mathrm{dl}$ in subjects, with STEMI (14). Because, atherothrombosis is a proinflammatory condition, it is important to describe the pro-inflammatory effects of glucose and the anti-inflammatory and other relevant effects of insulin, that are independent of its glucose lowering effect (15). Glucose induces reactive oxygen species generation, an increase in the expression of p47phox, as a marker of nicotinamide adenine dinucleotide phosphate oxidase, the enzyme that generates superoxide from molecula oxygen. In addition, glucose induces, an increase in nuclear factor kappa B (NF_B) binding, a reduction in inhibitor _B_, an increase in activating protein-1 and matrix metalloproteinases, and an increase in early growth response-1 and tissue factor (15). In STEMI, acute hyperglycemia is associated with an increase in no reflow, increased platelet aggregation, and increased left ventricular remodeling (15). Insulin, in contrast, suppresses reactive oxygen species generation, p47 phox; NF_B binding, early growth response-1 binding, tissue factor, and plasminogen activator inhibitor type 1 concentration (15). More recently, insulin has been shown to suppress the expression of toll-like receptors (TLR), in particular, TLR-2 and -4 (16). Both are involved in the pathogenesis of insulin resistance, whereas TLR-2 is involved the mediation of ischemia reperfusion injury and is thus particularly relevant to patients with AMI. In addition, insulin is a vasodilator, induces nitric oxide generation and the endothelial form of nitric oxide synthase expression, and inhibits platelet aggregability, both in normal subjects and in patients, with acute coronary syndromes (15).

\section{Effect of Stress Hyperglycaemia in Acute Myocardial Infarction}

An unusually high prevalence of glucosuria, in patients without diabetes who have acute myocardial infarction was noted, as far back as 1931.(17) Since then, up to half of these patients with acute myocardial infarction have been 
recognized as having raised blood glucose concentration.(18-19) Moreover, a positive association between hyprglycemia, at the time of the event and mortality from myocardial infarction has been noted.(20) Although, the mechanisms underlying this association are not fully understood, evidence that use of insulin to lower glucose concentrations decreases mortality in patients with diabetes who have myocardial infarction suggests that hyperglycaemia is not simply an epiphenomenon of the stress response mediated by cortical nor adrenaline.(21)In patients who have had myocardial infarction, the lack of insulin associated with hyperglycaemia may lead to a decrease of glycolytic substrate for cardiac muscle and excessive free fatty acids.(21) these changes may reduce myocardial contractility at increased oxygen cost, lead to pump failure, and promote arrhythmias.(22)Consequently, hyperglycaemia at the time of myocardial infarction in patients with and without diabetes may be an important and potentially modifiable risk factor for poor outcome.(22) There is a positive association between the plasma glucose, at the time of acute myocardial infarction and mortality in patients with and without diabetes.(23) The patients, with hyperglycaemia were significantly less likely to have Thrombolysis, in myocardial infarction trial (TIMI) grade 3 (normal) flow, before PCI compared to those with normoglycemia (12 versus 28 percent, adjusted odds ratio 2.6 for the absence of reperfusion). (24) The impairment in coronary flow might reflect a prothrombotic state, or endothelial dysfunction associated with hyperglycaemia or more sever disease, lead to a greater stress response. (24)

\section{Aims of the Study}

- To study the effect of stress hyperglycemia, on the development of cardiogenic shock, heart failure, arrhythmia, and death.

- To determine, whether the site of myocardial infarction has an effect on development of stress hyperglycemia.

- To determine whether this hyperglycemia occurs, more in patients who receive thrombolytic therapy or in those who do not receive it.

\section{PATIENTS AND METHODS}

This is a prospective randomized study had enrolled 92 patient with acute myocardial infarction in Baghdad teaching hospital (Emergency department, coronary care unit and medical ward) over 1 year from the first of December 2011 to the first of December 2012.

The patients had been studied without assessment of other risk factors for Ischemic heart diseases like hypertension, obesity, smoking, dyslipidemia and family history of ischemic heart diseases.

\section{Exclusion criteria}

- Patients with history of diabetes mellitus, heart failure, chronic renal failure

- Patients receiving steroid therapy.

- Patients with previous ECG finding of LBBB.

- Patients with previous ACS.

- $\quad \mathrm{HbA1c}>6.5$.

Full history was taken from each patient and full clinical examination was performed. 
The 12 leads ECG, in addition to cardiac TroponinI (qualitative test) was done for each patient, in emergency department and repeated in CCU and medical ward.

STEMI was defined based on the criteria established by current guidelines as persistent ( $>30$ min) retrosternal pain associated with ST segment elevation $>0.1 \mathrm{mV}$, in two or more limb leads or $>0.2 \mathrm{mV}$ in two or more pericardial leads, or acute left bundle branch block (LBBB), with biochemical evidence of myocardial necrosis ( $>1$ positive biochemical cardiac necrosis markers measurement)(25-26).

Random plasma glucose was done for each patient, by the usual laboratory method in the emergency department, at time of admission before receiving any treatment and repeated in the second day, after hospitalization (2nd day fasting blood glucose).

Admission hyperglycemia was diagnosed, if mean random glucose level on admission was $\geq 11.1 \mathrm{mmol} / \mathrm{L}$. Post admission hyperglycemia was diagnosed, if mean post admission fasting glucose level, calculated from glucose value on the morning after admission $\geq 7.8 \mathrm{mmol} /$ L. $(27-28)$

HbA1C level was measured in all patients, blood draw from patient and send to Baghdad teaching Laboratories. All patients with HbA1c level > 6.5\% were dropped from the study due to high probability to have undiagnosed diabetes.

The patients were divided into 2 groups: $\mathrm{g}$

Group 1: normoglycemic patients (no hyperglycaemia after AMI)

Group 2: stress hyperglycaemic patients (hyperglycaemia after AMI)

Echocardiography was done to all patients, with acute myocardial infarction in coronary care unit and systolic heart failure, considered to be present if the ejection fraction is less than $40 \%$ and may manifest as regional wall motion abnormalities. (30)

The diagnosis of cardiogenic shock, depend on clinical examination like hypotension (systolic blood pressure $<90$ $\mathrm{mmHg}$ ), cold clammy skin, rapid shallow breathing, drowsiness, irritability, confusion, oliguria (urine output $<30 \mathrm{ml} / \mathrm{hr}$ ) and supported, by echo cardiography. (31)

The site of myocardial infarction was recorded for each patient (lateral, inferior, anterior or extensive infarction) according to electrocardiographic reading; where a serial standard 12 lead ECG remain useful method for the detection and localization of myocardial infarction. (32)

\section{Statistical Analysis of the Data}

By using SPSS, (statistical package for social sciences) version 19 software, for windows; Data of all patients were entered and analysed. Appropriate statistical tests were performed and multiple contingency tables had been conducted. Student (t)-test, was used to find the significance of differences inbetween groups in mean age, and Chi square test was used to compare frequencies and proportions (percentages). Level of significance was set at $P$. value $\leq 0.05$ to be considered statistically significant and highly significant, if at P. value $\leq 0.01$. Finally, the results were presented in tables and or figures.

\section{RESULTS}


There were 92 patient enrolled in this study 60 patients (40 (66.7\%) males and $20(33.3 \%)$ females) in group 1 with a mean age of $(58 \pm 6.3)$ years and the range was $(42-83)$ years, and 32 patients (18 (56.25\%) males and $14(43.75 \%)$ females) in group 2 with a mean age of $(60 \pm 6)$ years and ranged (44-73) years.

No statistical significance had been found in between both groups regarding the age and genders, P. value $>0.05$, table 1 .

Table 1: The Demographic Features of the Patients

\begin{tabular}{|l|l|c|c|c|}
\hline \multicolumn{2}{|c|}{ Demographic Variable } & Group-1 & Group-2 & P. Value \\
\hline \multirow{3}{*}{ Age } & Number & $\mathbf{6 0}$ & $\mathbf{3 2}$ & - \\
\cline { 2 - 4 } & Rean \pm SD & $58 \pm 6.3$ & $60 \pm 5.8$ & \multirow{2}{*}{0.13} \\
& Range & $42-83$ & $44-73$ & NS \\
\hline \multirow{3}{*}{ Gender } & Male NO.(\%) & $40(66.7 \%)$ & $18(56.25 \%)$ & \multirow{2}{*}{0.44} \\
\cline { 2 - 4 } & Female No. (\%) & $20(33.3 \%)$ & $14(43,75 \%)$ & NS \\
\cline { 2 - 4 } & F:M ratio & $1: 2$ & $1: 1.14$ & \\
\hline
\end{tabular}

As it had been shown in table 2, The Prevalence of heart failure was significantly higher in group 2; 14 patients with heart failure out of 32 patients $(43.7 \%)$ versus 8 patients out of $60(13.3 \%)$ in group 1

Table 2: Frequency Distribution of Heart Failure among Study Groups

\begin{tabular}{|l|c|c|c|c|}
\hline \multirow{2}{*}{ Heart Failure } & \multicolumn{2}{|c|}{ Group-1 } & \multicolumn{2}{c|}{ Group-2 } \\
\cline { 2 - 5 } & No. & \% & No. & \% \\
\hline Heart failure & 8 & 13.3 & 14 & 43.7 \\
\hline No heart failure & 52 & 86.7 & 18 & 56.3 \\
\hline Total & $\mathbf{6 0}$ & $\mathbf{1 0 0}$ & $\mathbf{3 2}$ & $\mathbf{1 0 0}$ \\
\hline
\end{tabular}

Odds ratio $=5.1(95 \%$ CI $(1.82-14.03))$ P. value $=0.0026$

Four patients out of $60(6 \%)$ in group-1 developed cardiogenic shock, compared to 8 patients out of 32 (25\%) in group 2 , p value $<0.05$, the prevalence of cardiogenic shock was significantly higher, in patients with stress hyperglycemia in table 3 .

Table 3: Frequency Distribution of Cardiogenic Shock among Study Groups

\begin{tabular}{|l|l|l|l|l|}
\hline \multirow{2}{*}{ Cardiogenic shock } & \multicolumn{2}{|c|}{ Group-1 } & \multicolumn{2}{c|}{ Group-2 } \\
\cline { 2 - 5 } & NO. & \% & NO. & $\%$ \\
\hline Present & 4 & 6.6 & 8 & 25.0 \\
\hline Absent & 56 & 93.4 & 24 & 75.0 \\
\hline Total & 60 & 100 & 32 & 100 \\
\hline
\end{tabular}

Odds ratio $=4.7(95 \% \mathrm{CI}(1.28-16.9)) \mathrm{P}$. value $=0.030$

Table 4, show the site of myocardial infarction according to ECG findings among study groups, In group-1, there were 6 patients with inferolateral wall myocardial infarction, 14 patients with lateral wall myocardial infarction, 8 patients with inferior wall myocardial infarction, 12 patients with anterior wall myocardial infarction and 20 patients with extensive myocardial infarction, while in group-2 there were two patients with inferolateral wall myocardial infarction, 4 patients with lateral wall myocardial infarction, two patients with inferior wall myocardial infarction, 4 patients with anterior wall myocardial infarction and 20 patients with extensive myocardial infarction. So extensive MI was significantly more frequent among group $2(\mathrm{p}=0.013)$ 
Table 4: Frequncy Distribution of Sites of MI among Study Groups

\begin{tabular}{|l|c|c|c|c|c|}
\hline \multirow{2}{*}{\multicolumn{1}{|c|}{ Site of MI }} & \multicolumn{2}{|c|}{ Group-1 } & \multicolumn{2}{c|}{ Group-2 } & \multirow{2}{*}{ P. value } \\
\cline { 2 - 5 } & NO. & $\mathbf{\%}$ & NO. & \% & \\
\hline Inferolateral & 6 & 10.0 & 2 & 6.2 & $0.82 \mathrm{NS}$ \\
\hline Lateral & 14 & 23.3 & 4 & 12.5 & $0.33 \mathrm{NS}$ \\
\hline Inferior & 8 & 13.3 & 2 & 6.2 & $0.49 \mathrm{NS}$ \\
\hline Anterior & 12 & 20.0 & 4 & 12.5 & $0.14 \mathrm{NS}$ \\
\hline Extensive & 20 & 33.4 & 20 & 62.6 & $0.013 \mathrm{Sig}$ \\
\hline Total & $\mathbf{6 0}$ & $\mathbf{1 0 0}$ & $\mathbf{3 2}$ & $\mathbf{1 0 0}$ & \\
\hline
\end{tabular}

The prevalence of arrythemias did not significantly differ between both groups ( $\mathrm{p}$ value>0.05) and many different types of cardiac rhythm abnormalities were noticed, in table 5.

Table 5: Correlation of Arrhythmia to Stress Hyperglycemia

\begin{tabular}{|l|c|c|c|c|}
\hline \multirow{2}{*}{ Arrhythmia } & \multicolumn{2}{|c|}{ Group-1 } & \multicolumn{2}{c|}{ Group-2 } \\
\cline { 2 - 5 } & NO. & \% & NO. & \% \\
\hline VF & 6 & 10.0 & 4 & 12.5 \\
\hline VT & 8 & 13.3 & 4 & 12.5 \\
\hline AF & 6 & 10.0 & 6 & 18.8 \\
\hline SVT & 0 & 0 & 0 & 0 \\
\hline Heart block & 4 & 6.7 & 4 & 12.5 \\
\hline No arrhythmia & 36 & 60.0 & 14 & 43.7 \\
\hline Total & $\mathbf{6 0}$ & $\mathbf{1 0 0}$ & $\mathbf{3 2}$ & $\mathbf{1 0 0}$ \\
\hline
\end{tabular}

72 patients out of $92(78 \%)$, were subjected to thrombolytic therapy, while 20 of 92 (22\%) did not received this medication.

24 patients (33\%) out of 72who received thrombolytic therapy developed stress hyperglycemia and 8 patients $(40 \%)$ out of 20 , who did not received thrombolytic therapy developed stress hyperglycemia

There was no significant difference in the development of stress hyperglycemia, after acute MI in relation to thrombolytic therapy ( $\mathrm{p}$ value $>0.05$ ) as in table 6 .

Table 6: Correlation of Thrombolytic Therapy to Stress Hyperglycemia

\begin{tabular}{|c|c|c|c|c|c|c|}
\hline \multirow{2}{*}{$\begin{array}{c}\text { Patients Received } \\
\text { Thrombolytic } \\
\text { Therapy }\end{array}$} & \multicolumn{2}{|c|}{ Group-1 } & \multicolumn{2}{c|}{ Group-2 } & \multicolumn{2}{c|}{ Total } \\
\cline { 2 - 7 } & NO. & $\boldsymbol{\%}$ & NO. & $\%$ & NO. & $\%$ \\
\hline Yes & 48 & 67.0 & 24 & 33.0 & 72 & $100 \%$ \\
\hline No & 12 & 60.0 & 8 & 40.0 & 20 & $100 \%$ \\
\hline Total & $\mathbf{6 0}$ & $\mathbf{6 5 . 2}$ & $\mathbf{3 2}$ & $\mathbf{3 4 . 8}$ & $\mathbf{9 2}$ & $\mathbf{1 0 0 \%}$ \\
\hline
\end{tabular}

$P$. value $=0.77 \mathrm{NS}$

The death was significantly more frequent in group -2 in comparison to group-1, there were 12 patients died out of 32 patients (37\%) in group-2, versus 6 patients died out of 60 patients (10\%) in group-1, P. value $<0.05$ as in table 7. 
Table 7: Frequency Distribution of Death among Study Groups

\begin{tabular}{|l|c|c|c|c|c|c|}
\hline \multirow{2}{*}{ Death } & \multicolumn{2}{|c|}{ Group-1 } & \multicolumn{2}{c|}{ Group-2 } & \multicolumn{2}{c|}{ Total } \\
\cline { 2 - 7 } & NO. & $\boldsymbol{\%}$ & NO & \% & NO & \% \\
\hline Died & 6 & 10.0 & 12 & 37.0 & 18 & 19.60 \\
\hline Survive & 54 & 90.0 & 20 & 63.0 & 74 & 80.40 \\
\hline Total & $\mathbf{6 0}$ & $\mathbf{1 0 0}$ & $\mathbf{3 2}$ & $\mathbf{1 0 0}$ & $\mathbf{9 2}$ & $\mathbf{1 0 0}$ \\
\hline
\end{tabular}

Odds ratio $=5.4(95 \% \mathrm{CI}(1.8-16.3)) \mathrm{P}$. value $=0.0038$ highly significant

\section{DISCUSSIONS}

The study showed that the incidence of heart failure and cardiogenic shock were more in patients with stress hyperglycemia and this is consistent with Bellodi G. et al. (33), which showed that, hyperglycemia with acute myocardial infarction is associated with increased risk of heart failure and cardiogenic shock.

The high incidence of heart failure and cardiogenic shock can be explained by multiple reasons, including that hyperglycemia could reduce flow to the risk area (34), resulting in greater myocardial damage, before the reperfusion(35), acute increase in bloodglucose levelworsen endothelial function (36), therefore suggesting that, hyperglycemia induced endothelial dysfunction can also contributes to the damaging effect of hyperglycemia, during an acute myocardial infarction, acute hyperglycemia independently associated with impaired left ventricular function(37) and a large infarct size, due to an increased incidence of the no re-flow phenomenon (38).

The study showed that, patients with extensive infarction seem to develop stress hyprglycemia, more than those patients with lateral, inferior, inferolateral or anterior myocardial infarction probably, due to large infarct size in those patients, with extensive infarction this consistent with Tansey MJ. et al. (39)

This study showed that, stress hyperglycemia was not associated with an increased incidence of arrhythmia inconsistent with A. Sandaram et al.(40) showed that, hyperglycemia was associated with great erincidence of conductive defect and arrhythmia. Gokhroo R. et al.(41) showed that, in acute myocardial infarction, an increased plasma glucose level have been demonstrated to be capable of inducing, such electro phsyological alterations as to favour the occurrence of arrhythmias, whose outcome could be fatal. This is consistent with the evidence that, an acute increase in blood glucose level in normal subjects produces a significant QT prolongation (42).

In this study, there were no significant differences in patients, who received thrombolytic therapy from those patients, who did not receive thrombolytic therapy, in relation to stress hyperglycemia inconsistent with Nicholas A. et al., (43) which showed that, thrombolytic therapy preserves left ventricular function and reduces mortality, after AMI.

This study, showed the incidence of death was more in patients, with stress hyperglycemia, where there were 12 patients, out of 32 patients died (37\%) and this is consistent with Bolk J. et al (44) showed that, hyperglycemia is associated with increased mortality, after AMI.

\section{CONCLUSIONS}

- Stress hyperglycemia is independently a poor prognostic factor, in acute ST elevation myocardial infarction; it is independently associated with increased incidence of heart failure, cardiogenic shock and death. 
- Patients with extensive myocardial infarction, are more liable to get stress hyperglycemia.

- Stress hyperglycemia is not associated, with increased incidence of cardiac arrhythmia.

\section{REFERENCES}

1. DeWood MA, Spores J, Notske R, et al. Prevalence of total coronary occlusion during the early hours of transmural myocardial infarction. N Engl J Med 1980; 303:897-902.

2. Falk E. Coronary thrombosis: pathogenesis and clinical manifestations. Am J Cardiol 1991; 68:28B-35B.

3. Reznik, AG. Morphology of acute myocardial infarction at prenecrotic stage. Kardiologiia2010; 50 (1): 4-8.

4. Moe KT, Wong P). Current trends in diagnostic biomarkers of acute coronary syndrome. Ann. Acad. Med. Singap.2010; 39 (3): $210-5$.

5. Killip T, 3rd, Kimball JT. Treatment of myocardial infarction in a coronary care unit. A two year experience with 250 patients. Am J Cardiol 1967;20:457 64.

6. Terrence D. Welch, MD, Eric H. Yang, et al. Modern Management of Acute Myocardial Infarction. Curr Probl Cardiol 2012;37:237-310.

7. Antman EM, Anbe DT, Armstrong PW, et al. ACC/AHA guidelines for the management of patients with ST-elevation myocardial infarction: a report of the American College of Cardiology/American Heart Association Task Force on Practice Guidelines (committee to revise the 1999 guidelines for the management of patients with acute myocardial infarction). Circulation 2004; 110:e82-292.

8. Nestler DM, White RD, Rihal CS, et al. Impact of prehospital electrocardiogram protocol and immediate catheterization team activation for patients with STElevation- Myocardial infarction. Circ Cardiovasc Qual Outcomes 2011;4: 640-6.

9. Sgarbossa EB, Pinski SL, Barbagelata A, et al. Electrocardiographic diagnosis of evolving acute myocardial infarction in the presence of left bundle-branch block. N Engl J Med 1996; 334:481-7.

10. Thygesen K, Alpert JS, White HD, et al. Universal definition of myocardial infarction. Circulation 2007; 116:2634-53.

11. Ohman EM, Armstrong PW, Christenson RH, et al. Cardiac troponin $T$ levels for risk stratification in acute myocardial ischemia. GUSTO IIA investigators. N Engl J Med 1996; 335:1333-41.

12. Goyal A, Mahaffey KW, Garg J, et al. Prognostic significance of the change in glucose level in the first 24 h after acute myocardial infarction: results from the CARDINAL study. Eur Heart J 2006; 27: 1289-97.

13. Kosiborod M, Inzucchi SE, Krumholz HM, et al. Glucometrics in patients hospitalized with acute myocardial infarction: defining the optimal outcomes based measure of risk. Circulation 2008; 117: 1018-27.

14. Deedwania P, Kosiborod M, Barrett E, et al. Hyperglycemia and acute coronary syndrome: a scientific statement from the American Heart Association Diabetes Committee of the Council on Nutrition, Physical Activity, and Metabolism. Circulation 2008; 117:1610-9.

15. Dandona P, Chaudhuri A, Ghanim H, Mohanty P. Effect of hyperglycemia and insulin in acute coronary syndromes. Am J Cardiol 2007; 99:12H-8H.

16. Ghanim H, Mohanty P, Deopurkar R, et al. Acute modulation of toll-like receptors by insulin. Diabetes Care 2008; 31:182731 .

17. Cruikshank N. Coronary thrombosis and myocardial infarction, with glycosuria. BMJ 1931; 1: 618-19. 
18. Sewdarsen M, Jialal I, Vythilingum S, Govender G, Rajput MC. Stress hyperglycemias is a predictor of abnormal glucose tolerance in Indian patients with acute myocardial infarction. Diabetes Res 1987; 6: 47-49

19. Oswald GA, Smith CCT, Betteridge DJ, Yudkin JS. Determinants and importance of stress hyperglycemias in non-diabetic patients with myocardial infarction. BMJ 1986; 293:917-22.

20. Yudkin JS, Oswald GA. Hyperglycemia,diabetes and myocardial infarction. Diabetes Med 1987; 4: 13-18.

21. Malmberg K. Ryden L. Efeddic S. et al, on behalf of the DIGAMI Study Group. A randomised trial of insulin-glucose infusion followed by subcutaneous insulin treatment in diabetic patients with acute myocardial infarction: effects on mortality at 1 year. J Am Coll Cardiol 1995; 26:57-65.

22. Oliver MF, Opie LH. Effects of glucose and fatty acids on myocardial ischemia and arrhythmias. Lancet 1994; 343: 155-58.

23. Capes SE, Hunt, D,Malmberg,K,Gerstein,HC. Stress hyperglycemia and increased risk of death after myocardial infarction in patients with and without diabetes: asystemic overview. Lancet 2000;355:773-778.

24. Timmer, JR, Ottervanger, JP, de Boer, MJ, et al. Hyperglycaemia is an important predictor of impaired coronary flow before reperfusion therapy in ST-elevation myocardial infarction. J Am CoLL Cardiol 2005; 45:999.

25. Thygesen K, Alpert JS, White HD, on behalf of the Joint ESC/ACCF/AHA/WHF Task Force for the Redefinition of myocardial infarction. Universal definition of myocardial infarction. Eur Heart J. 2007; 28:2525-38.

26. Van de Werf F, Bax J, Betriu A, Blomstrom Lundqvist C, Crea F, Falk V, et al. Management of acute myocardial infarction in patients presenting with persistent ST-segment elevation. The Task Force on the management of ST-segment elevation acute myocardial infarction of the European Society of Cardiology. Eur Heart J. 2008; 29:2909-45.

27. Taysir S. Garadah, Salah Kassab,Qasim M. Al-Shboul et al. The Threshold of Admission Glycemia as a Predictor of Adverse Events in Diabetic and Non-Diabetic Patients with Acute Coronary Syndrome. Cardiology.2009; 3:29-36.

28. Sandram,A. C. R. Anand Moses. Stress hyperglycaemia and acute myocardial infarction. INT. J. Diab. Countries 1995; 15:129.

29. Alvin C. Powersl. Harrison 's principles of internal medicine.2005; $16: 2172$.

30. Eugene Braunwald. Harrison's principles of internal medicine.2005;16:1371.

31. Nieminen MS, Bohm M, Cowie MR et al. Executive summary of the guidelines on the diagnosis and treatment of acute heart failure: the task force on acute heart failure of the European Society of Cardiology. Eur Heart J 2005; 26:384-416.

32. Murray, C., and alpert, J. S. :Diagnosis of acute myocardial infarction. Curro pin. Cardiol. 9:465,1994.

33. Bellodi G,Manicurdi V,Malavasi $V$ et al. Hyperglycemia and prognosis of acute myocardial infarction in patient without diabetes mellitus. AmJ cardiol.1989;64:885-888.

34. Kersten JR, Toller WG, Tessmer JP et al. Hyperglycemia reduce coronary collateral blood flow through a nitric oxidemediated mechanism. Am J physical heart sirc. Physiol.2001;281:H2097-H2104.

35. Iwakurak, Ito H, Kawano $S$ et al. Predictor factors for the development of the no-reflow phenomenon in patients with reperfused anterior myocardial infarction. J Am Coll cardiology 2001;38:472-477.

36. Williams SB, Goldfine AB,Timimi FK et al. Acute hyperglycemia attenuates endothelium-dependent vasodilatation in humans in vivo. Circulation 1998;97:1695-1701.

37. Ishihara M, Inoue I, Kawagoe et al. Impact of acute hyperglycemia on left ventricular function after reperfusion therapy in 
patients with a first anterior wall myocardial infarction. Am Heart J 2003;146:674-678.

38. Iwakurak, Ito H, Kawano S et al. Predictor factors for the development of the no-reflow phenomenon in patients with anterior myocardial infarction. J Am Coll cardiology 2003;41:1-7.

39. Tansey MJ, Opie LH. Plasma glucose on admission to hospital as a metabolic index of the severity of acute myocardial infarction. Can J Cardiol 1986;2:326-331.

40. Sandram,A. C. R. Anand Moses. Stress hyperglycaemia and acute myocardial infarction. INT. J. Diab. Countries 1995; $15: 127$.

41. Gokhroo R,Mittal SR. Electrocardiographic correlates of hyperglycemia in acute myocardial infarction. Int $J$ cardiolog 1989;22:267-269.

42. Marfella $R$, Nappo F,De Angelis L et al. the effect of acute hyperglycemia on QTc duration in healthy man. Diabetalogia 2000;43:571-575.

43. Nicholas A. Boon Nicki R. College Brian R. Walker, John A. A. Hunter. Davidson s principles and practice of medicine 2006;20:595.

44. Bolk J, Van Der Ploeg T,Cornel JH, Arnold AE et al. Impaired glucose metabolism predicts mortality after amyocardial infarction. Int J Cardiol.2001;79:207-214. 
